\title{
Sliding Mode Control With Grid Voltage Modulated DPC for Voltage Source Inverters Under Distorted Grid Voltage
}

\author{
Yonghao Gui, Qianwen Xu, Frede Blaabjerg, and Hong Gong
}

\begin{abstract}
The grid voltage modulated direct power control (GVM-DPC) for grid-connected voltage source inverters has been introduced so that it can overcome the poor steady-state performance of the DPC. However, it was designed for a nondistorted grid voltage. In this paper, the GVM-DPC is modified to overcome a distorted grid voltage (e.g., fifth and seventh harmonics). First, a band pass filter is applied to extract the fundamental component of the voltage so as to build a model for the implementation of the GVM-DPC method. Next, a sliding mode control (SMC) is designed to handlethe terms of the harmonic in order to minimize the total harmonic distortion (THD) of the output currents. Simulations and experimental results are presented to verify the effectiveness of the proposed SMC with GVM-DPC control strategy. It is shown that although the performance of real and reactive powers are sacrificed, the THD of the current is significantly reduced.
\end{abstract}

Index Terms-Distorted grid voltage, grid voltage modulated direct power control (GVM-DPC), sliding mode control, total harmonic distortion (THD), voltage source inverter.

\section{INTRODUCTION}

$\mathrm{R}_{\mathrm{f}}^{\mathrm{t}}$ ECENTLY, due to the rapid development of smart grid, flexible ac transmission systems, high voltage dc systems, and renewable energy sources (e.g., wind, photovoltaic, and fuel cells, etc.), there has been a tremendous increase in the use of voltage source inverters (VSIs) [1]-[12]. For VSI applications, the voltage oriented control (VOC) strategy is widely applied in order to inject currents into the grid as a current source [13].

In a standard VOC method, real and reactive power is controlled indirectly by controlling $d-q$ axes currents separately in a synchronous rotating reference frame [13]. By using coordinate transformation, the VOC method transforms the ac values (three-phases) to the dc ones; the dynamics of VSI is changed into a linear time-invariant (LTI) system in the

Manuscript received June 30, 2019. (Corresponding Author: Yonghao Gui.) Y. Gui is with the Automation \& Control Section at the Dept. Electronic Systems, Aalborg University, 9220 Aalborg, Denmark (e-mail: yg@es.aau.dk).

Q. Xu is with the School of Electrical and Electronic Engineering, Nanyang Technological University, Singapore (e-mail: qianwen.xu@ntu.edu.sg).

F. Blaabjerg and H. Gong are with the Dept. Energy Technology, Aalborg University, 9220 Aalborg, Denmark (e-mail: fbl@et.aau.dk, hgo@et.aau.dk).

Digital Object Identifier 10.24295/CPSSTPEA.2019.00023 synchronous rotating reference frame, and thus the VSI system can be easily designed and analyzed by using the linear control techniques [14]-[18]. However, the phase-locked loop (PLL) is a key component for the grid synchronization in VOC method, where the PLL will negatively affect the stability of VSIs in a weak grid condition [19]-[21].

Direct power control (DPC), another control method for VSIs, has been researched to control instantaneous real and reactive powers directly without using any inner-loop current regulator and PLL system [22], [23]. However, these methods will cause an unexpected broadband harmonic spectrum range due to the variable switching frequency according to the switching state. In order to obtain a constant switching frequency, some other DPC strategies using space vector modulation [23], [24] or calculating required converter voltage vector in each switching period [25], [26] have been proposed. Moreover, to enhance the robust property of the system, a sliding mode control (SMC) based DPC and a passivity-based control DPC strategies are proposed to make the system exponentially converge to its real and reactive power references with consideration of the system model, even there exist parameter uncertainties [27], [28]. However, ripples in both real and reactive powers are still conspicuous as well as in the currents. In addition, model predictive control (MPC)-DPC, as an optimal control approach, has been applied for VSIs [29]-[31]. With the MPCDPC algorithm, it is easy to solve the multi-variable case and consider system's nonlinearities and constraints in an intuitive way. However, one of the disadvantages is that it may increase computational burden.

Recently, a DPC strategy is designed in a synchronous rotating reference frame, where a virtual phase angle is used instead of the one estimated by the PLL [32], [33]. In general, however, the DPC strategies are designed in stationary reference frame instead of the synchronous rotating reference frame for the simplification [23]-[28]. In addition, a novel DPC strategy called grid voltage modulated-DPC (GVM-DPC) has been designed for grid connected VSIs, where the poor steadystate performance of the DPC methods is solved [34]-[36]. However, the model of the GVM-DPC method is obtained based on a strong assumption, which needs a non-distorted grid voltage. Normally, due to the nonlinear loads connected into the girds, the grid voltage is harmonically distorted. The effects of such harmonics may be increased in terms of losses, 
heating and loss-of-life of equipment, and interference with control, protection and communication circuits as well as customer loads [37]. For these reasons, some works have been researched to handle such harmonics distortions [38]-[41].

In this paper, how to apply the GVM-DPC method in a distorted grid is shown, where the measured voltage will negatively affect the injected current from the VSI. At first, in order to consider the fundamental component of the measured voltage, a band-pass-filter (BPF) is used to extract the fundamental part. Then, a fundamental component of real and reactive powers model can be obtained, i.e., the GVM-DPC concept can be applied directly. Hence, in this paper, an SMC control strategy, which is one of the best methods for tracking problem [42], [43], is employed to handle the harmonics terms as well as minimization of the total harmonic distortion (THD) of the output currents. The proposed control architecture is validated in MATLAB/Simulink, Simscape Power Systems. Although the performance of the real and reactive powers is sacrificed, the THD of the current is significantly reduced. Finally, the effectiveness of the proposed method is tested in a prototype experimental setup.

The rest of the paper is organized as follows. The system modeling of the grid-connected VSI based on the DPC model after using the BPF, and a GVM-DPC algorithm with a simple structure with feedforward and feedback is designed in Section II. Then, an SMC is additionally designed to minimize the THD of the current in Section III. Section IV shows the simulation results using MATLAB/Simulink, Simscape Power Systems and experimental results using a $15 \mathrm{~kW}$ prototype VSI. Finally, Section V gives the conclusions of this study.

\section{Grid Voltage Modulated Direct Power Control for Distorted Grid}

In this section, a VSI model in terms of the DPC is introduced based on a BPF. In addition, a GVM-DPC strategy is employed to the VSI system in order to obtain an LTI system.

\section{A. Modeling of Voltage Source Inverters}

As shown in Fig. 1, a two-level three-phase VSI with an $L$-filter is connected to the grid. It is assumed that a stiff dc source is used to be connected at the dc-side of VSI in this study. For example, a rectifier of wind application or a dcdc converter of solar photovoltaic is connected. Thus, the dynamic from the dc input will be ignored in this study. For the conventional DPC with PWM method, the instantaneous real and reactive powers are calculated and controlled to generate the voltage references for the PWM [26], [27].

From Fig. 1, the dynamic equations can be expressed as follows:

$$
\begin{aligned}
& L \frac{\mathrm{d} i_{L, a}}{\mathrm{~d} t}=-R i_{L, a}+v_{\mathrm{inv}, a}-v_{\mathrm{g}, a}, \\
& L \frac{\mathrm{d} i_{L, b}}{\mathrm{~d} t}=-R i_{L, b}+v_{\mathrm{inv}, b}-v_{\mathrm{g}, b}, \\
& L \frac{\mathrm{d} i_{L, c}}{\mathrm{~d} t}=-R i_{L, c}+v_{\mathrm{inv}, c}-v_{\mathrm{g}, c},
\end{aligned}
$$

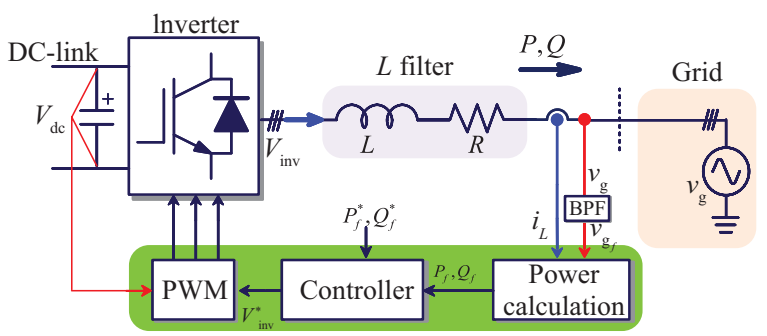

Fig. 1. Single-line diagram of three-phase voltage source inverter with a direct power controller.

where $i_{a b c}, v_{\mathrm{g}, a b c}$, and $v_{\text {inv, } a b c}$ are the VSI output current, the grid voltage, and the VSI output voltage in the abc frame, respectively. In addition, $L$ is the filter inductance, and $R$ is the filter resistance. Based on a balanced grid voltage condition, (1) is able to transform in the stationary reference frame by using Clark transformation [44] as follows:

$$
\begin{aligned}
& L \frac{\mathrm{d} i_{L, \alpha}}{\mathrm{d} t}=-R i_{L, \alpha}+v_{\mathrm{inv}, \alpha}-v_{\mathrm{g}, \alpha}, \\
& L \frac{\mathrm{d} i_{L, \beta}}{\mathrm{d} t}=-R i_{L, \beta}+v_{\mathrm{inv}, \beta}-v_{\mathrm{g}, \beta},
\end{aligned}
$$

where $i_{L, \alpha \beta}, v_{\mathrm{g}, \alpha \beta}$, and $v_{\text {inv, }, \beta}$ indicate the output currents, the grid voltages, and the inverter output voltages (control inputs) in the stationary reference frame, respectively.

It should be noted that the GVM-DPC firstly introduced in [45] considers a non-distorted grid voltage condition. In a distorted grid, however, the measured voltage negatively affects the injected current in the GVM-DPC structure. In order to use the benefits of the GVM-DPC concept, only fundamental frequency of the distorted grid voltage is considered by using a BPF in the controller, where the injected currents will be generated by the GVM-DPC the fundamental ones as well. It is acceptable since from the grid side, it is expected that only the fundamental of real and reactive powers are to be generated to the grid. Hence, the fundamental component of the measured grid voltages are obtained by a BPF, given by

$$
v_{g, \alpha \beta_{f}}=G_{\mathrm{BPF}} \cdot v_{\mathrm{g}, \alpha \beta},
$$

where $v_{\mathrm{g}, \alpha \beta_{f}}$ indicates the fundamental component of the distorted grid voltages, and $G_{\mathrm{BPF}}$ indicates the transfer function of the BPF. Consequently, the instantaneous fundamental component of real and reactive powers generated to the grid can be obtained by using the stationary reference frame as follows [46], [47]:

$$
\begin{aligned}
& P_{f}=\frac{3}{2}\left(v_{\mathrm{g}, \alpha_{f}} i_{L, \alpha}+v_{\mathrm{g}, \beta_{f}} i_{L, \beta}\right), \\
& Q_{f}=\frac{3}{2}\left(v_{\mathrm{g}, \beta_{f}} i_{L, \alpha}-v_{\mathrm{g}, \alpha_{f}} i_{L, \beta}\right),
\end{aligned}
$$

where $P_{f}$ and $Q_{f}$ represent the fundamental component of the instantaneous real and reactive powers generated to the 
grid, respectively. By differentiating (4) with respect to time, the dynamic equations of the fundamental component of instantaneous real and reactive powers is obtained such as

$$
\begin{aligned}
& \frac{\mathrm{d} P_{f}}{\mathrm{~d} t}=\frac{3}{2}\left(i_{L, \alpha} \frac{\mathrm{d} v_{\mathrm{g}, \alpha_{f}}}{\mathrm{~d} t}+v_{\mathrm{g}, \alpha_{f}} \frac{\mathrm{d} i_{L, \alpha}}{\mathrm{d} t}+i_{L, \beta} \frac{\mathrm{d} v_{\mathrm{g}, \beta_{f}}}{\mathrm{~d} t}+v_{\mathrm{g}, \beta_{f}} \frac{\mathrm{d} i_{L, \beta}}{\mathrm{d} t}\right), \\
& \frac{\mathrm{d} Q_{f}}{\mathrm{~d} t}=\frac{3}{2}\left(i_{L, \alpha} \frac{\mathrm{d} v_{\mathrm{g}, \beta_{f}}}{\mathrm{~d} t}+v_{\mathrm{g}, \beta_{f}} \frac{\mathrm{d} i_{L, \alpha}}{\mathrm{d} t}-i_{L, \beta} \frac{\mathrm{d} v_{\mathrm{g}, \alpha_{f}}}{\mathrm{~d} t}-v_{\mathrm{g}, \alpha_{f}} \frac{\mathrm{d} i_{L, \beta}}{\mathrm{d} t}\right) .
\end{aligned}
$$

Since $v_{\mathrm{g}}$ is fundamental component of the distorted grid voltages, the following relationship holds

$$
v_{\mathrm{g}, \alpha_{f}}=V_{\mathrm{g}_{f}} \cos \left(\omega_{f} t\right), v_{\mathrm{g}, \beta_{f}}=V_{\mathrm{g}_{f}} \sin \left(\omega_{f} t\right)
$$

where $V_{\mathrm{g}_{f}}$ represents the magnitude of the fundamental grid voltages. $\omega_{f}=2 \pi f$ represents the angular frequency of the fundamental component of the distorted grid voltages, where $f$ represents the fundamental frequency of the distorted grid voltage. By differentiating (6) with respect to time, the instantaneous fundamental grid voltages have the following relationships:

$$
\begin{aligned}
\frac{\mathrm{d} v_{\mathrm{g}, \alpha_{j}}}{\mathrm{~d} t} & =-\omega_{f} V_{\mathrm{g}_{f}} \sin \left(\omega_{f} t\right)=-\omega_{f} v_{\mathrm{g}, \beta_{f}}, \\
\frac{\mathrm{d} v_{\mathrm{g}, \beta_{f}}}{\mathrm{~d} t} & =\omega_{f} V_{\mathrm{g}_{f}} \cos \left(\omega_{f} t\right)=\omega_{f} v_{\mathrm{g}, \alpha_{f}} .
\end{aligned}
$$

Substituting (2) and (7) into (5), the state-space models of the fundamental component of real and reactive powers are given as follows [48]:

$\frac{\mathrm{d} P_{f}}{\mathrm{~d} t}=-\frac{R}{L} P_{f}-\omega_{f} Q_{f}+\frac{3}{2 L}\left(v_{\mathrm{g}, \alpha_{f}} v_{\mathrm{inv}, \alpha}+v_{\mathrm{g}, \beta_{f}} v_{\mathrm{inv}, \beta}-V_{\mathrm{g} f}^{2}\right)$,

$\frac{\mathrm{d} Q_{f}}{\mathrm{~d} t}=\omega_{f} P_{f}-\frac{R}{L} Q_{f}+\frac{3}{2 L}\left(v_{\mathrm{g}, \beta_{f}} v_{\mathrm{inv}, \alpha}-v_{\mathrm{g}, \alpha_{f}} v_{\mathrm{inv}, \beta}\right)$.

It should be noted that, the dynamics of instantaneous real and reactive powers in (8) are a multi-input-multi-output (MIMO) system, where $v_{\text {inv }, \alpha}$ and $v_{\text {inv }, \beta}$ represent the control inputs and $P_{f}$ and $Q_{f}$ are the outputs. Moreover, the system is a time-varying one since both control inputs are multiplied by the grid voltages, which are sinusoidal.

\section{B. Controller Design}

In order to obtain an LTI system, the GVM-DPC inputs are defined as follows:

$$
\begin{aligned}
& u_{P}=v_{\mathrm{g}, \alpha_{f}} v_{\mathrm{inv}, \alpha}+v_{\mathrm{g}, \beta_{f}} v_{\mathrm{inv}, \beta}-V_{\mathrm{g} f}^{2}, \\
& u_{Q}=v_{\mathrm{g}, \beta_{f}} v_{\mathrm{inv}, \alpha}-v_{\mathrm{g}, \alpha_{f}} v_{\mathrm{inv}, \beta},
\end{aligned}
$$

where $u_{P}$ and $u_{Q}$ represent the new control inputs, which should be designed instead of the original control inputs. Based on the GVM-DPC inputs in (9), the dynamic equations of the real and reactive powers in (8) is represented as

$$
\begin{aligned}
& \frac{\mathrm{d} P_{f}}{\mathrm{~d} t}=-\frac{R}{L} P_{f}-\omega Q_{f}+\frac{3}{2 L} u_{P}, \\
& \frac{\mathrm{d} Q_{f}}{\mathrm{~d} t}=\omega P_{f}-\frac{R}{L} Q_{f}+\frac{3}{2 L} u_{Q} .
\end{aligned}
$$

Now, the time varying system in (8) is transformed into an LTI MIMO system with the coupling states.

The errors of the real and reactive powers are defined as follows:

$$
e_{P}=P_{f}^{*}-P_{f}, e_{Q}=Q_{f}^{*}-Q_{f},
$$

where $P_{f}^{*}$ and $Q_{f}^{*}$ represent the desired references of the real and reactive powers, respectively.

Theorem 1. [45] For the MIMO system in (10), a control law is designed as

$$
\begin{aligned}
& u_{P}=\frac{2 R}{3} P_{f}+\frac{2 L \omega_{f}}{3} Q+K_{P, p} e_{P}, \\
& u_{Q}=-\frac{2 L \omega_{f}}{3} P+\frac{2 R}{3} Q_{f}+K_{Q, p} e_{Q},
\end{aligned}
$$

where $K_{P, p}$ and $K_{Q, p}$ are the controller gains. If $K_{P, p}$ and $K_{Q, p}$ are positive values, then the errors of real and reactive powers globally exponentially converge to zeros.

Proof. Taking the derivative of (11) and substituting (12) into (11) yield

$$
\begin{aligned}
& \frac{\mathrm{d} e_{P}}{\mathrm{~d} t}=\frac{R}{L} P_{f}+\omega Q_{f}-\frac{3}{2 L} u_{P}, \\
& \frac{\mathrm{d} e_{Q}}{\mathrm{~d} t}=-\omega P_{f}+\frac{R}{L} Q_{f}-\frac{3}{2 L} u_{Q} .
\end{aligned}
$$

With the control input designed as (12), (13) is expressed as

$$
\frac{\mathrm{d} e_{P}}{\mathrm{~d} t}=-\frac{3}{2 L} K_{P, p} e_{P}, \frac{\mathrm{d} e_{Q}}{\mathrm{~d} t}=-\frac{3}{2 L} K_{Q, P} e_{Q} .
$$

By selecting controller gains as positive values, the closedloop system is exponentially stable in the operating range. i.e., the errors exponentially converge to zero.

Finally, the original control inputs of the VSI in (2) can be generated by means of (9) such as

$$
\begin{gathered}
v_{\mathrm{inv}, \alpha}=\frac{v_{\mathrm{g}, \alpha_{f}} u_{P}+v_{\mathrm{g}, \beta_{f}} u_{Q}+V_{\mathrm{g} f}^{2} v_{\mathrm{g}, \alpha_{f}}}{V_{\mathrm{g}_{f}}^{2}}, \\
v_{\mathrm{inv}, \beta}=\frac{v_{\mathrm{g}, \beta_{f}} u_{P}-v_{\mathrm{g}, \alpha_{f}} u_{Q}+V_{\mathrm{g} f}^{2} v_{\mathrm{g}, \beta_{f}}}{V_{\mathrm{g}_{f}}^{2}} .
\end{gathered}
$$

\section{Stability Analysis}

In this paper, the transfer function of the BPF is given by

$$
G_{\mathrm{BPF}}=\frac{2 \omega_{c} s}{s^{2}+2 \omega_{c} s+\omega_{0}^{2}},
$$


where $\omega_{c}$ and $\omega_{0}$ are the resonance bandwidth and resonance frequency, respectively. In addition, $\omega_{c}=\zeta \omega_{0}$, where $\zeta$ is the damping ratio. The state-space model of the $\mathrm{BPF}$ is represented as

$$
\begin{aligned}
& \dot{x}_{\mathrm{BPF}}=\left[\begin{array}{cccc}
-2 \omega_{c} & -\omega_{0}^{2} & 0 & 0 \\
1 & 0 & 0 & 0 \\
0 & 0 & -2 \omega_{c} & -\omega_{0}^{2} \\
0 & 0 & 1 & 0
\end{array}\right] x_{\mathrm{BPF}}+\left[\begin{array}{ll}
1 & 0 \\
0 & 0 \\
0 & 1 \\
0 & 0
\end{array}\right] u_{\mathrm{BPF}}, \\
& y_{\mathrm{BPF}}=\left[\begin{array}{cccc}
2 \omega_{c} & 0 & 0 & 0 \\
0 & 0 & 2 \omega_{c} & 0
\end{array}\right] x_{\mathrm{BPF}} .
\end{aligned}
$$

where $x_{\mathrm{BPF}}$ is the state variable, $u_{\mathrm{BPF}}=\left[v_{\mathrm{g}, \alpha}, v_{\mathrm{g}, \beta}\right]^{T}$ is the control input, and $y_{\mathrm{BPF}}=\left[v_{\mathrm{g}, \alpha, \rho}, v_{\mathrm{g}, \beta, \beta}\right]^{T}$ is the output.

In [48], the stability analysis for a weak grid-connected inverter was given. In this study, only a stiff grid is considered, i.e., the line impedance is zero, Consequently, the error dynamics could be obtained based on [48] as

$$
\dot{e}=\dot{x}^{d}-\dot{x}=A e
$$

where $x=\left[i_{L, \alpha}, i_{L, \beta}, x_{\mathrm{BPF}}\right]^{T} \in R^{6}, u=\left[v_{\mathrm{g}, o}, v_{\mathrm{g}, \beta}\right]^{T} \in R^{6}$, subscript ' $d$ ' indicates desired value. Moreover, $A$ is listed in (19).

In order to check the effect of the BPF in the control method, $\zeta$ is changed from 0.9 to 0.1 , as shown in Fig. 2(a). It is observed that a pair of the eigenvalues are closer to the imaginary when $\zeta$ is decreased from Fig. 2(b). However, all the eigenvalues remain in the left-half plane, i.e., the closed loop system is stable.

\section{COMPENSATOR FOR HARMONICS}

In the aforementioned section, the GVM-DPC method only compensates the fundamental part. However, the harmonics terms of the grid voltage are still affecting the current. Thus, an SMC strategy will be designed to minimize the distortion in the current.

The grid voltage could be expressed as follows:

$$
\begin{aligned}
& v_{g, \alpha}=\sum_{i=1}^{n} V_{g_{i}} \cos \left(\omega_{i} t\right), \\
& v_{g, \beta}=\sum_{i=1}^{n} V_{g_{i}} \sin \left(\omega_{i} t\right),
\end{aligned}
$$

where $V_{\mathrm{g}_{i}}$ and $\omega_{i}$ are the magnitude and angular frequency of $i$-th

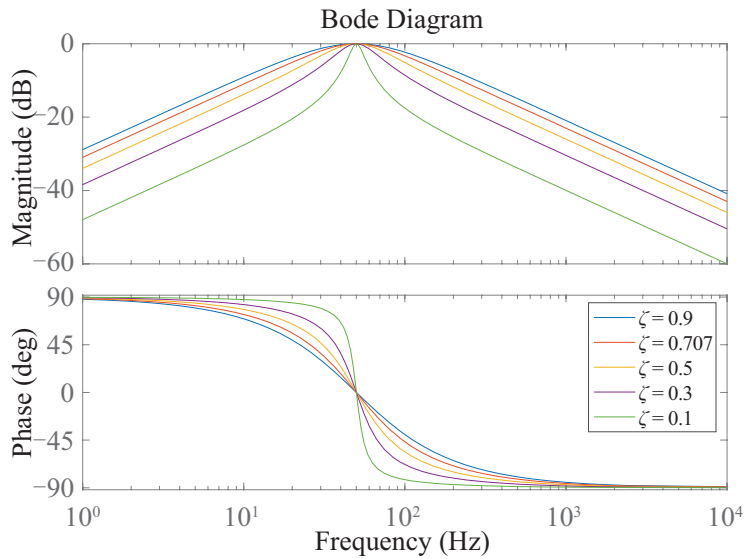

(a)

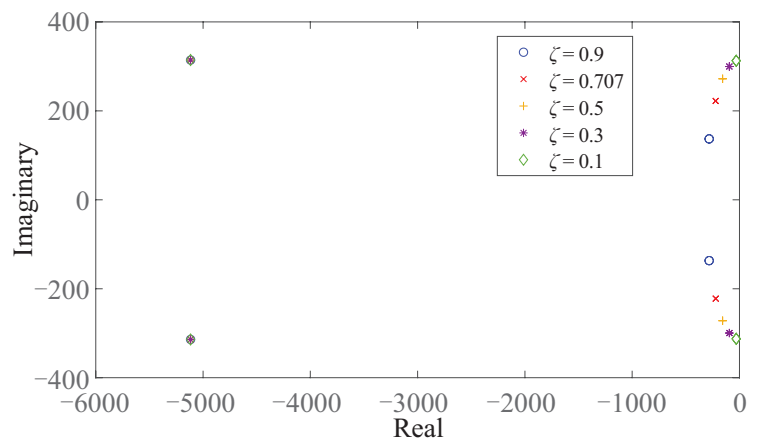

(b)

Fig. 2. Eigenvalues of the closed-loop system when the damping ratio $\zeta$ is changed from 0.9 to 0.1 .

order of the grid voltages, respectively. Considering from (3) to (10), the real and reactive powers model from 2 to $n$-th could be obtained such as

$$
\begin{aligned}
\frac{\mathrm{d} P_{i}}{\mathrm{~d} t} & =-\frac{R}{L} P_{i}-\omega_{i} Q_{i}+\frac{3}{2 L} u_{P_{i}}, \\
\frac{\mathrm{d} Q_{i}}{\mathrm{~d} t} & =\omega_{i} P_{i}-\frac{R}{L} Q_{i}+\frac{3}{2 L} u_{Q_{i}},
\end{aligned}
$$

where $i=2, \ldots, n$. Let's define the $i$-th errors of the real and reactive powers as follows:

$$
\begin{aligned}
& e_{P_{i}}=P_{i}^{*}-P_{i}, \\
& e_{Q_{i}}=Q_{i}^{*}-Q_{i} .
\end{aligned}
$$

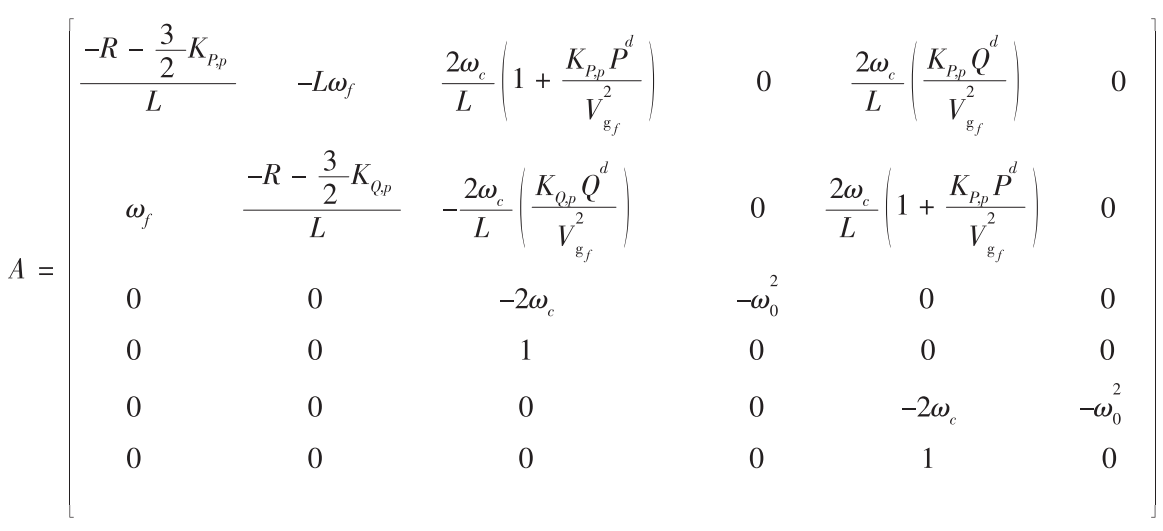


Next, let's define sliding surfaces as follows:

$$
\begin{aligned}
& s_{P_{i}}=K_{P_{i}} e_{P_{i}}, \\
& s_{Q_{i}}=K_{Q_{i}} e_{Q_{i}},
\end{aligned}
$$

where $K_{P_{i}}$ and $K_{Q_{i}}$ are controller gains. The variable $s$ must satisfy the equation

$$
\begin{aligned}
& \dot{s}_{P_{i}}=K_{P_{i}} \dot{e}_{P_{i}}, \\
& \dot{s}_{Q_{i}}=K_{Q_{i}} \dot{e}_{Q_{i}} .
\end{aligned}
$$

Based on (21) and (24), the equivalent control can be obtained as follows:

$$
\begin{aligned}
& u_{P, e_{Q i}}=\frac{2 L}{3}\left(\frac{R}{L} P_{i}+\omega_{i} Q_{i}\right), \\
& u_{Q, e_{Q i}}=\frac{2 L}{3}\left(\omega_{i} P_{i}-\frac{R}{L} Q_{i}\right) .
\end{aligned}
$$

It should be noted that $P_{i}^{*}$ and $Q_{i}^{*}$ are 0 , where $i=2, \ldots, n$. To guarantee the reaching condition, a Lyapunov function candidate is selected as

$$
V=\frac{1}{2} \sum_{i=2}^{n}\left(s_{P_{i}}^{2}+s_{Q_{i}}^{2}\right) .
$$

Taking the derivative of the Lyapunov function candidate in (26) with respect to time results in

$$
\dot{V}=\sum_{i=2}^{n}\left(s_{P_{i}} K_{P_{i}} \dot{e}_{P_{i}}+s_{Q_{i}} K_{Q_{i}} \dot{e}_{Q_{i}}\right) .
$$

Design a control law as

$$
\begin{aligned}
& u_{P_{i}}=u_{P, e_{\varphi i}}+\frac{2 L}{3} K_{P_{s_{i}}} \operatorname{sat}\left(\frac{s_{P_{i}}}{\varepsilon}\right), \\
& u_{Q_{i}}=u_{Q, e_{Q i}}+\frac{2 L}{3} K_{Q_{s_{i}}} \operatorname{sat}\left(\frac{s_{Q_{i}}}{\varepsilon}\right),
\end{aligned}
$$

where $K_{P_{s i}}$ and $K_{Q_{s i}}$ are positive controller gains and $\varepsilon>0$, then in $s \geqslant \varepsilon$, the following inequality function yields

$$
\dot{V} \leqslant-\sum_{i=2}^{n}\left(K_{P_{s_{i}}}\left|s_{P_{i}}\right|+K_{Q_{s_{i}}}\left|s_{Q_{i}}\right|\right) \text {. }
$$

Note that, (29) shows the trajectory with the proposed method reaches its boundary layer in finite time, then in the boundary layer (i.e., $s<\varepsilon$ ), it will satisfy Theorem 1 . Finally, the original control inputs can be calculated based on (15) and (28) as well. Fig. 3 shows the block diagram of the proposed GVM-DPC with SMC method.

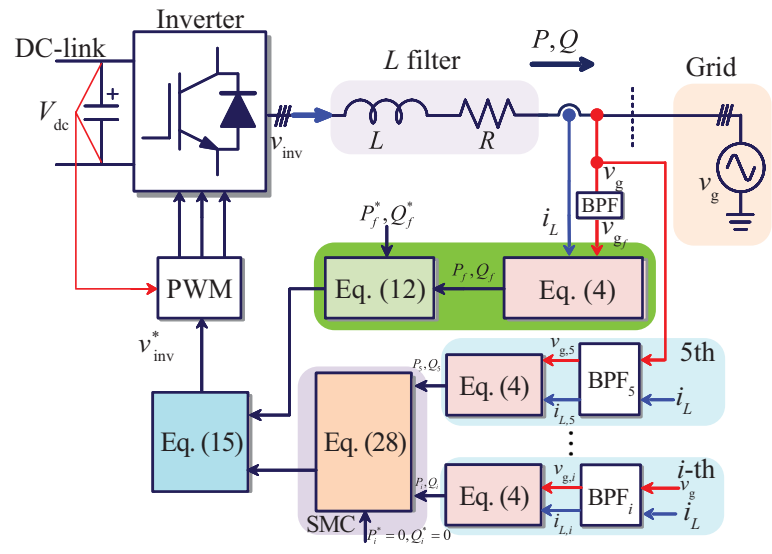

Fig. 3. Control block diagram of the voltage source inverter.

TABLE I

System Parameters Used in Simulation and Experimental Test

\begin{tabular}{lcc}
\hline \multicolumn{1}{c}{ Parameter } & Symbol & Value \\
\hline Nominal grid voltage & $V_{\mathrm{g} a \mathrm{rms}}$ & $110 \mathrm{~V}$ \\
Nominal grid frequency & $f$ & $50 \mathrm{~Hz}$ \\
DC-link voltage & $V_{\mathrm{dc}}$ & $730 \mathrm{~V}$ \\
Filter inductance & $L$ & $6 \mathrm{mH}$ \\
Filter resistance & $R$ & $0.15 \Omega$ \\
Damping ratio of BPFs & $\zeta$ & $0.707 \mathrm{p.u}$. \\
Resonance frequency of $\mathrm{BPF}$ & $\omega_{0}$ & $2 \pi * 50 \mathrm{rad} / \mathrm{s}$ \\
Resonance frequency of $\mathrm{BPF}_{5}$ & $\omega_{5}$ & $2 \pi * 250 \mathrm{rad} / \mathrm{s}$ \\
Resonance frequency of $\mathrm{BPF}_{7}$ & $\omega_{7}$ & $2 \pi * 350 \mathrm{rad} / \mathrm{s}$ \\
Switching frequency & $f_{\mathrm{SW}}$ & $10 \mathrm{kHz}$ \\
\hline \hline
\end{tabular}

\section{Performance Validation}

In this section, both simulation results using MAT-LAB/ Simulink, Simscape Power Systems and experimental results using a prototype experimental setup at Aalborg University are shown in order to validate the proposed method. The parameters of the system used in the simulation and experimental tests are listed in Table I. The proposed method is compared with the pure GVM-DPC and the GVM-DPC with a BPF methods. Note that the control parameters of the GVM-DPC could be selected based on the linear second-order system. For the BPF parameter, if the bandwidth of BPF is too narrow (i.e., $\zeta$ is too small.), it is not easy to handle a wide variation in grid. Otherwise, it is not easy to give sufficient attenuation in higher harmonic components presented in the grid voltage. It is a tradeoff. For the SMC parameters, if $\varepsilon$ is too small, it is easy to generate the chattering phenomenon. Otherwise, it can not generate sliding motion. It is a tradeoff as well. $K_{P S 5,7}$ and $K_{Q s 5,7}$ relate to the finite time when the trajectory converges to its sliding surface. The control parameters used in this paper is summarized in Table II.

\section{A. Simulation Results}

Typically, the fifth and seventh order harmonics distortions become a common adverse disturbance in the grid voltage 
TABLE II

Controller Gains Used in Simulation

\begin{tabular}{ccc}
\hline \hline & & Parameter \\
\hline \multirow{2}{*}{ GVM-DPC } & $K_{P, p}, K_{Q, p}$ & 20 \\
& $K_{P_{i}}, K_{Q_{i}}$ & 2000 \\
\hline \multirow{3}{*}{ SMC-DPC } & $K_{P_{5,7},}, K_{Q_{S, 7}}$ & 100 \\
& $K_{P_{S, 7},}, K_{Q_{S, 7}}$ & 10000 \\
& $\varepsilon_{P, Q}$ & 2000 \\
\hline \hline
\end{tabular}
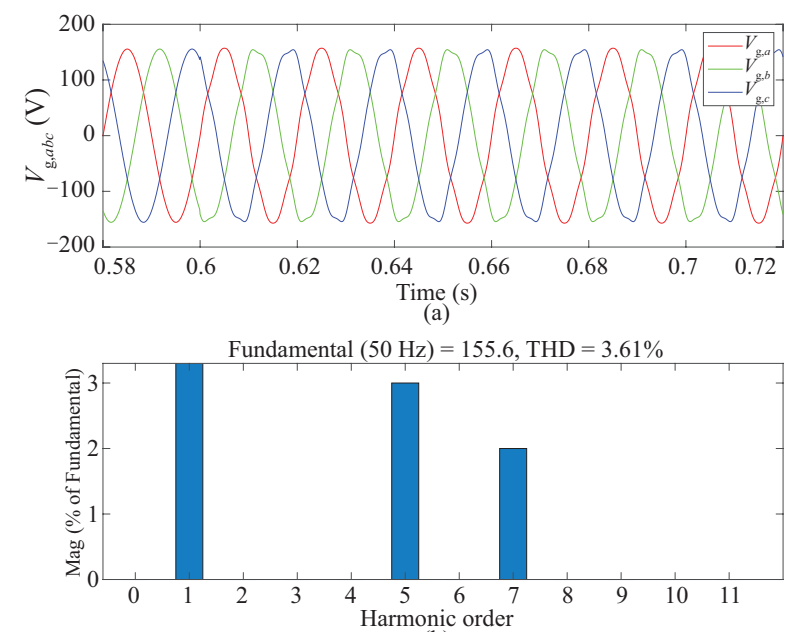

(b)

Fig. 4. (a) Grid voltage with 5th and 7th harmonics. (b) Spectrum analysis.

[37]. Fig. 4(a) shows the time response of grid voltages when 5 th and 7th harmonics are generated at $0.6 \mathrm{~s}$, where the THD of the voltage is $3.61 \%$, as shown in Fig. 4(b). In this case, the distorted grid voltages affect the control performance of the GVM-DPC method, as shown in Fig. 5. However, the real and reactive powers are regulated well with $P=10 \mathrm{~kW}$ and $Q=0$ Var, as shown in Fig. 5(a), which is the control target 1 proposed in [39]. However, the currents are affected by the distorted grid voltages and the THD is $3.62 \%$, which does not satisfy the IEEE standard for harmonic control in electric power systems [49]. To handle such problem, a candidate solution is to use a BPF to extract the fundamental part of the grid voltage. Even though the THD of the current is decreased to $1.45 \%$, as shown in Fig. 6(b). It should be noted that the performance of real and reactive powers is deteriorated automatically, as shown in Fig. 6(a). Two control targets for the achieving of low THD current and smooth real and reactive powers are contradictory [39], [50]. The THD with the GVMDPC and BPF is still high since the harmonics parts are left in the currents.

To overcome the weakness of GVM-DPC, the SMC is used to minimize the harmonics parts and improve the THD of the currents, as shown in Fig. 7. Although, the performance of real and reactive powers with the BPF is sacrificed, the quality of the current is increased. Table III summarizes the THD of the current with three methods. It is shown that the proposed method significantly reduces the THD of the current compared

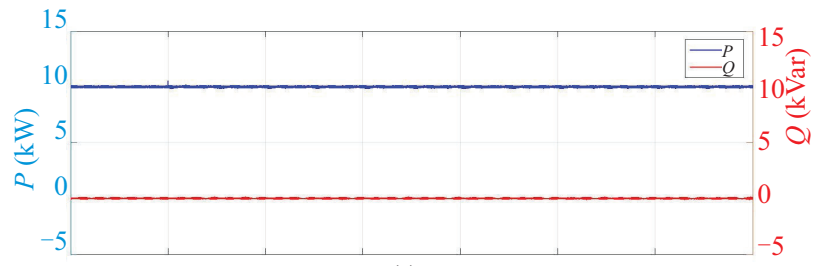

(a)

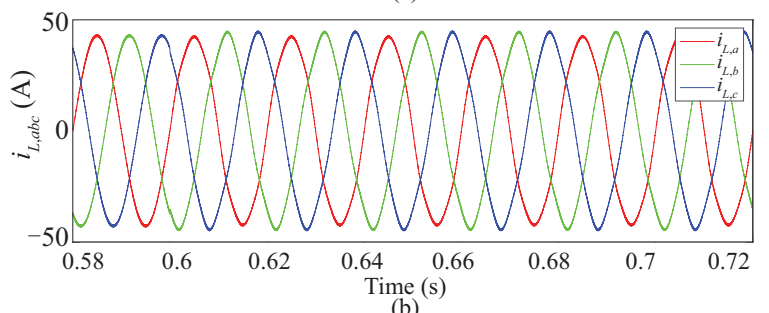

(b)

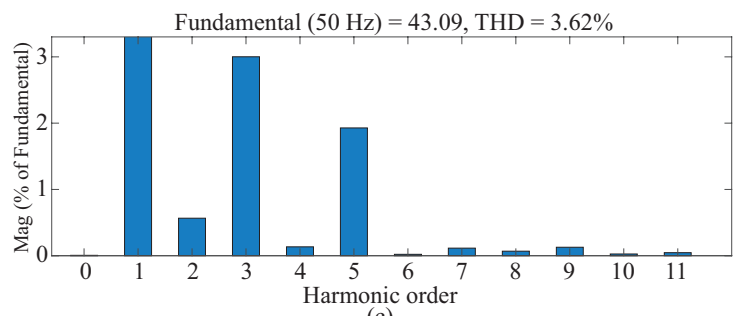

(c)

Fig. 5. Simulation results when using the GVM-DPC method. (a) Real and reactive powers. (b) Currents. (c) Current spectrum.

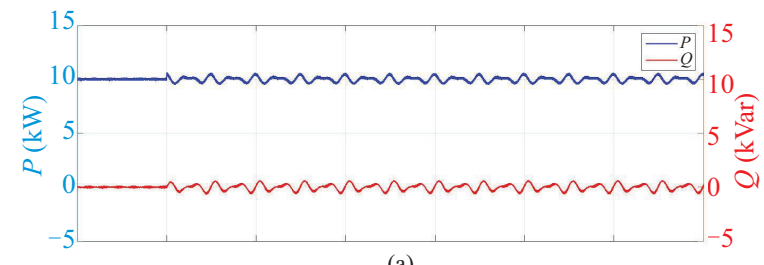

(a)

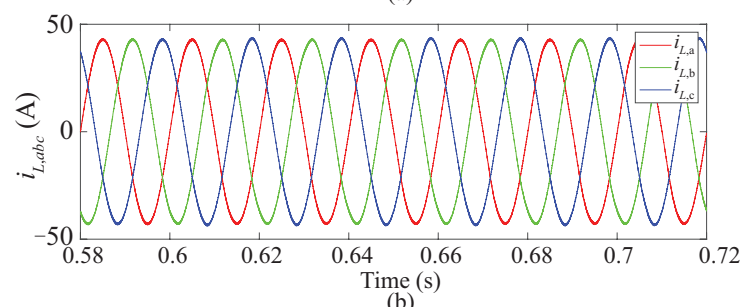

(b)

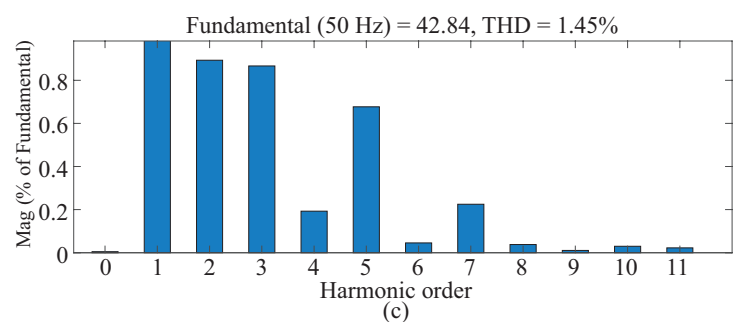

Fig. 6. Simulation results when using the GVM-DPC method with BPF. (a) Real and reactive powers. (b) Currents. (c) Current spectrum.

with other two methods, where the proposed method improves the harmonic suppression of $70.4 \%$ and $26.2 \%$, respectively. Fig. 8 shows the tracking performance with the proposed method when the grid voltage is distorted. It reveals that with 


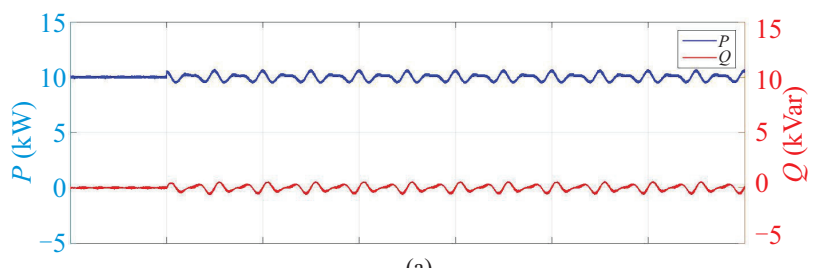

(a)
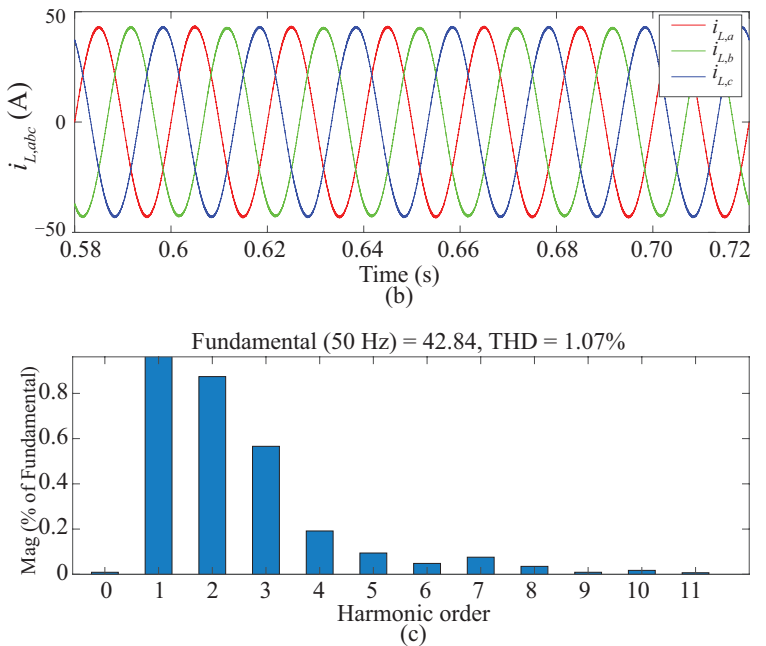

Fig. 7. Simulation results when using the proposed GVM-DPC and SMC method. (a) Real and reactive powers. (b) Currents. (c) Current spectrum.

TABLE III

Comparison of Three Methods Regarding the THD of Currents

\begin{tabular}{cccc}
\hline \hline Methods & GVM-DPC & GVM-DPC $_{\text {BPF }}$ & GVM+SMC \\
\hline THD & $3.62 \%$ & $1.45 \%$ & $1.07 \%$ \\
\hline \hline
\end{tabular}

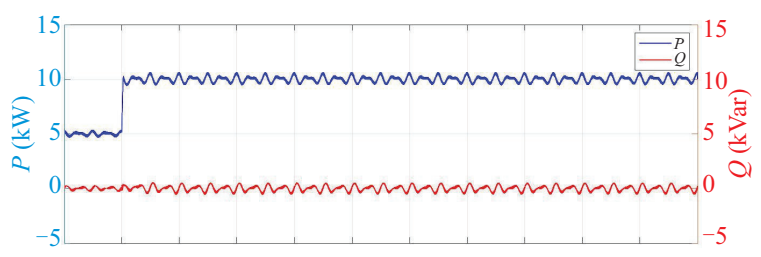

(a)

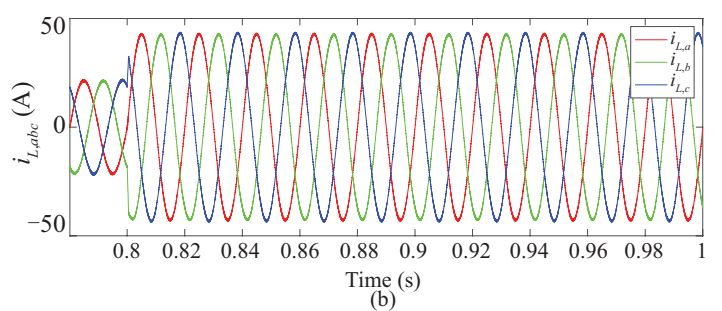

Fig. 8. Simulation results when real power is changed from $5 \mathrm{~kW}$ to $10 \mathrm{~kW}$ with 5 th and 7 th harmonics in grid voltage. (a) Real and reactive powers. (b) Currents.

the variation of real power reference, power tracking is well achieved. The associated trajectories and surfaces of are fifth and seventh order real and reactive powers are shown in Fig. 9.

Furthermore, the performance of the proposed method in the unbalanced and distorted grid voltage case is also tested, as shown in Fig. 10. The phase "A" has $10 \%$ sag at $0.7 \mathrm{~s}$, and
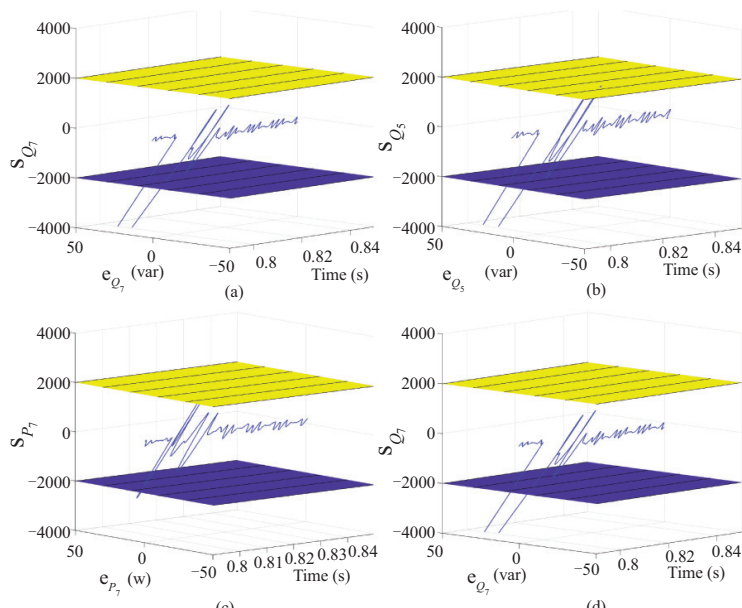

(d)

Fig. 9. Trajectories and surfaces of (a) 5th real power, (b) 5 th reactive power, (c) 7 th real power, and (d) 7 th reactive power.

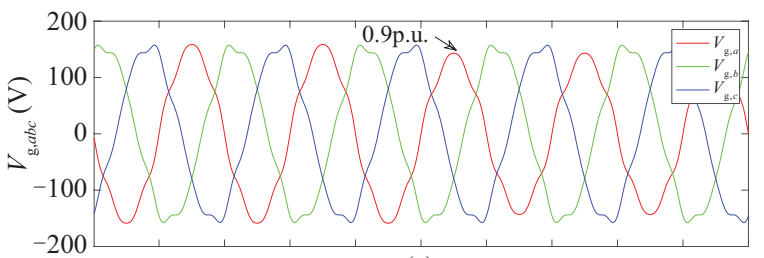

(a)

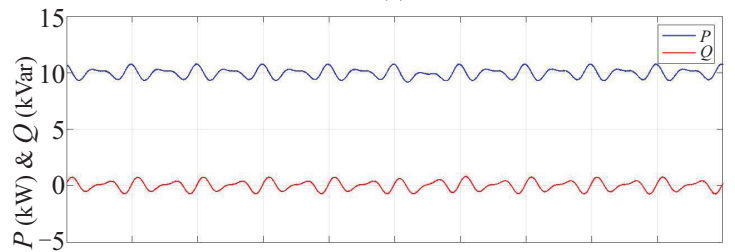

(b)

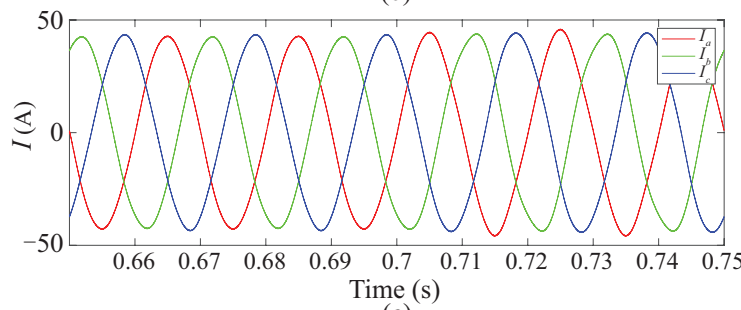

(c)

Fig. 10. Simulation results when the phase "A" has $10 \%$ sag at 0.7 s. (a) Grid voltage. (b) Real and reactive powers. (c) Currents.

all three-phase has 5\% 5th and 3\% 7th harmonics. It can be observed that the proposed method could reject the harmonics and inject the sinusoidal current to the grid as well, as shown in Fig. 10(c).

\section{B. Experimental Results}

The proposed method is implemented by using the DS1007 dSPACE system and tested by using a three-phase $15 \mathrm{~kW}$ inverter system at the Power Electronics Power Distribution Laboratory (Aalborg University, Denmark), as shown in Fig. 11(a). A grid simulator is used to support $110 \mathrm{~V}$ RMS grid voltage and generate the expected harmonics in the test. The 

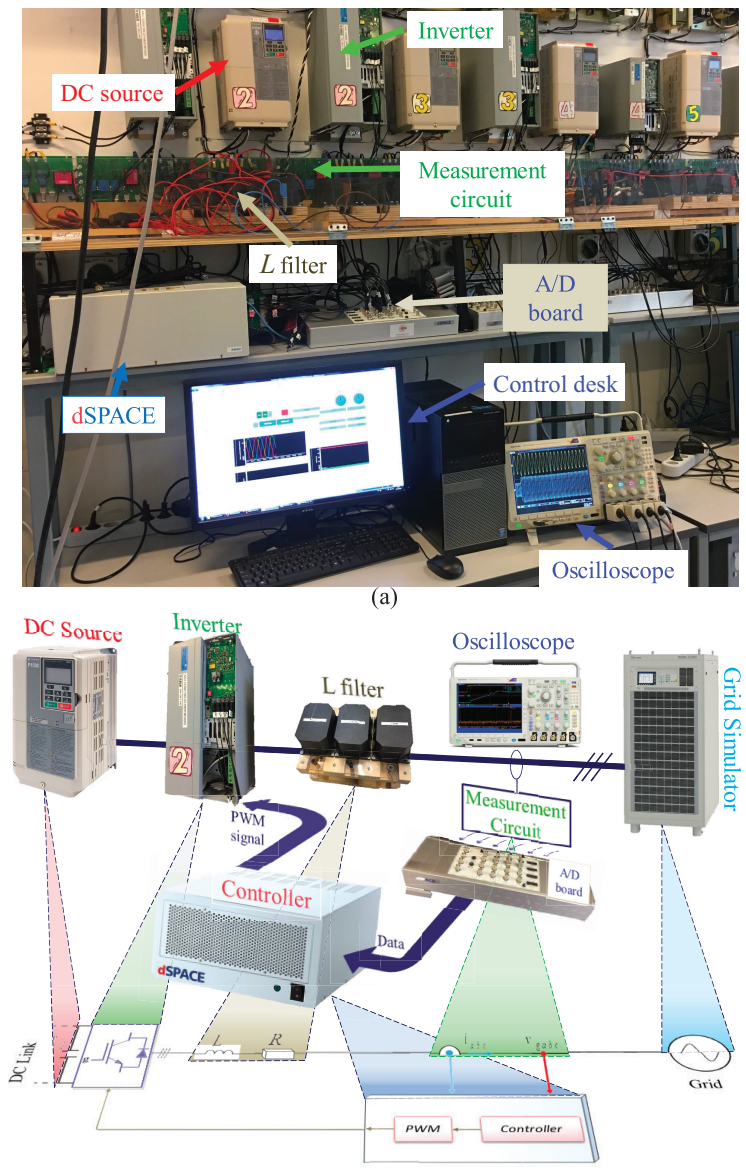

(b)

Fig. 11. (a) Experimental setup at Aalborg University. (b) Configuration.
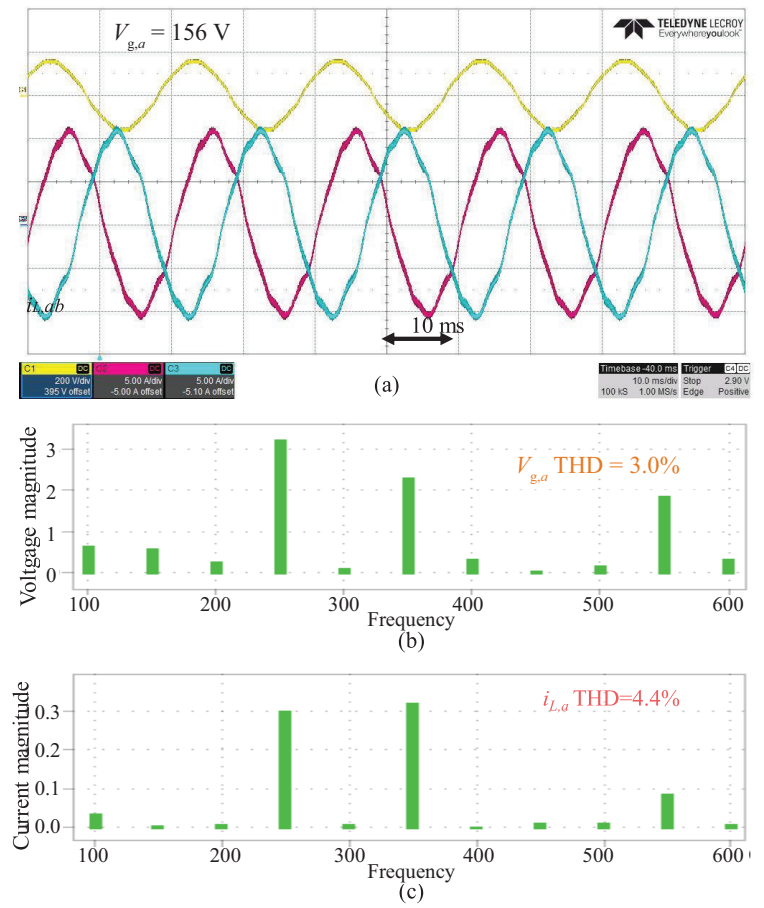

Fig. 12. GVM-DPC. (a) Measured performance (yellow line: grid voltage $v_{\text {g.a }}(150$ V/div); pink-red, sky-blue, and green lines: output currents $i_{L, a b c}(5 \mathrm{~A} /$ div $\left.)\right)$. (b) Spectrum analysis of voltage. (c) Spectrum analysis of current with 5th and 7th harmonics in grid voltage.
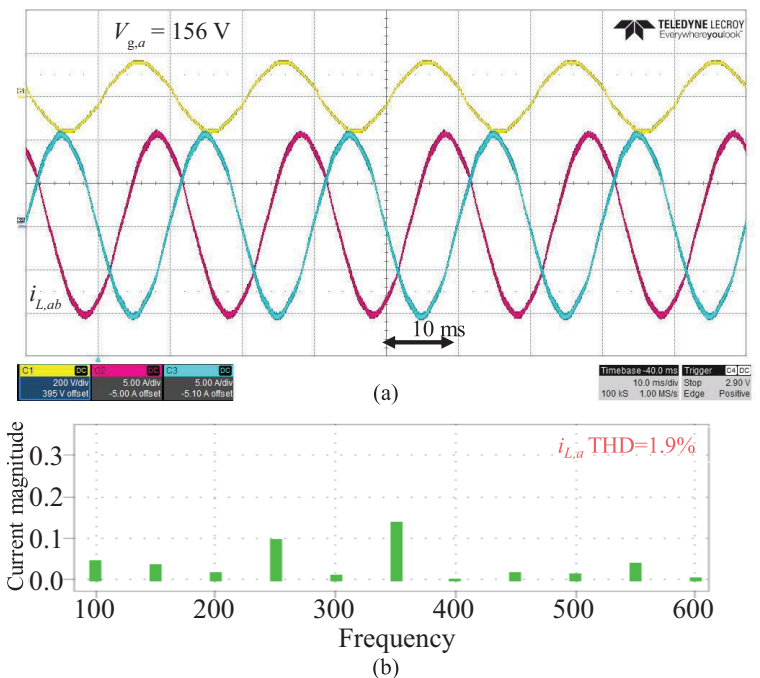

Fig. 13. GVM-DPC with BPF. (a) Measured performance (yellow line: grid voltage $v_{\mathrm{g}, a}(150 \mathrm{~V} /$ div $)$; pink-red, sky-blue, and green lines: output currents $\left.i_{L, a b c}(5 \mathrm{~A} / \mathrm{div})\right)$. (b) Spectrum analysis of current with 5 th and 7 th harmonics in grid voltage.
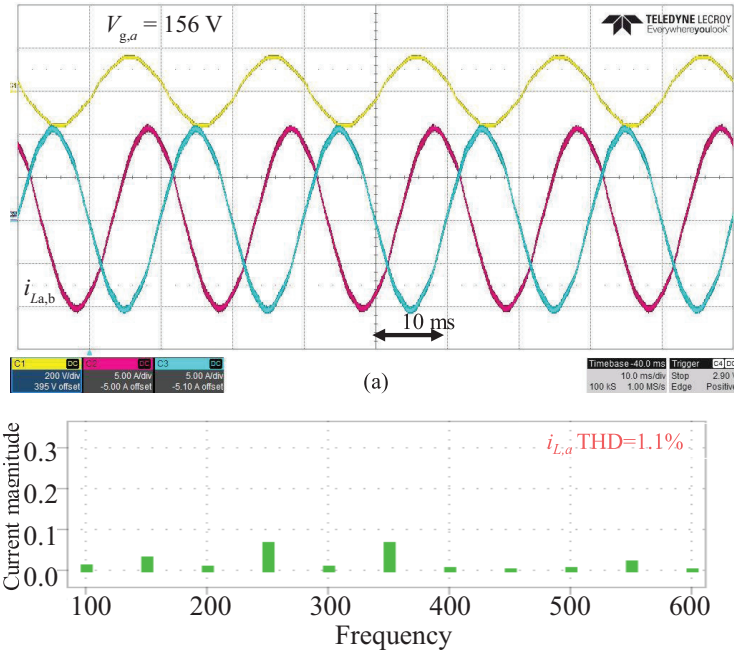

(b)

Fig. 14. GVM-DPC with SMC. (a) Measured performance (yellow line: grid voltage $v_{\mathrm{g}, a}(150 \mathrm{~V} / \mathrm{div})$; pink-red, sky-blue, and green lines: output currents $i_{L, a b c}(5 \mathrm{~A} /$ div $\left.)\right)$. (b) Spectrum analysis of current with 5 th and 7 th harmonics in grid voltage.

voltages and line currents are measured by using a DS2004 $\mathrm{A} / \mathrm{D}$ board, The configuration of the whole test system is summarized, as shown in Fig. 11(b). Both sampling and switching frequencies are set to $10 \mathrm{kHz}$.

At first, 5th and 7th harmonics are injected to the grid voltage by using the grid simulator, and the THD of the grid voltage is $5.8 \%$, as shown in Fig. 12(b). The performance of the inverter with the pure GVM-DPC method is affected by these harmonics, and the THD of the current increases to $6.4 \%$, as shown in Fig. 12. The performance of the GVM-DPC method with the BPF is improved, and the THD of the current decreases to $1.4 \%$, as shown in Fig. 13. However, with the proposed method, the THD of the current is smallest, $0.97 \%$, as shown in Fig. 14. Consequently, it can be concluded that the 


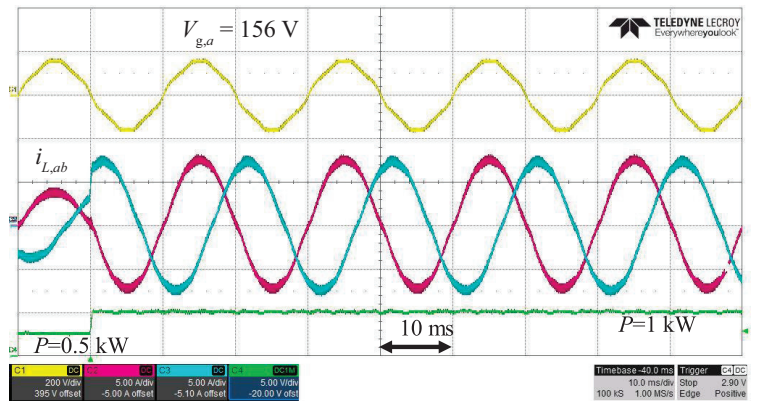

Fig. 15. Measured performance when the active power is changed from 0.5 $\mathrm{kW}$ to $1 \mathrm{~kW}$. (yellow line: grid voltage $v_{\mathrm{g}, a}(150 \mathrm{~V} /$ div); pink-red and sky-blue: output currents $i_{L, a b}(5 \mathrm{~A} / \mathrm{div})$; green line: active power $\left.P(1 \mathrm{~kW} / \mathrm{div})\right)$.

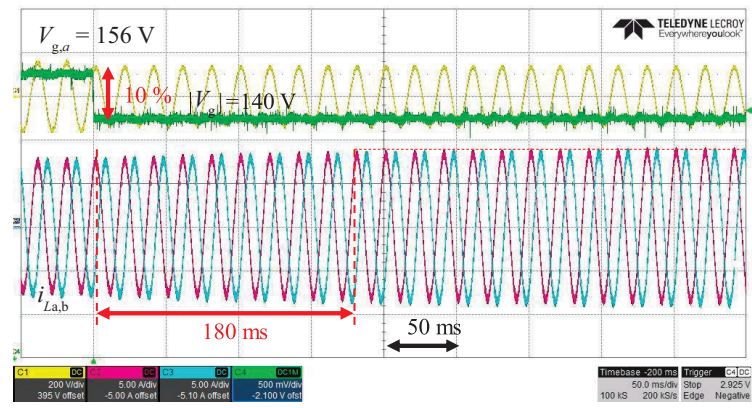

Fig. 16. Measured performance when the grid voltage has $10 \%$ sag (yellow line: grid voltage $v_{\mathrm{g}, a}(150 \mathrm{~V} / \mathrm{div})$; pink-red and sky-blue: output currents $i_{L, a b}(5$ $\mathrm{A} /$ div); green line: grid voltage magnitude $\left.V_{\mathrm{g}}(10 \mathrm{~V} / \mathrm{div})\right)$.

proposed method could effectively overcome the grid disturbed by harmonics, which can cause increased losses, equipment heating and loss-of-life, and interference with protection, control and communication circuits as well as customer loads. In addition Fig. 15 shows the time response with the proposed method when the active power is changed from $0.5 \mathrm{~kW}$ to $1 \mathrm{~kW}$. The time delay caused by the BPF does not affect its performance. However, when the grid voltage has $10 \%$ sag, the time delay generates a delayed current performance $(180 \mathrm{~ms}$ convergence time), as shown in Fig. 16, since the BPF is used for the grid voltage measurement.

\section{CONCLUSIONS}

In this paper, the GVM-DPC for three-phase VSI connected into a distorted grid was introduced to control instantaneous real and reactive powers. The BPF was used to obtain a fundamental model of VSI in order to apply the GVM-DPC. Moreover, the SMC was proposed to minimize the affect from the distorted voltage. Simulation and experimental results show that the proposed method effectively reduces the THD of the currents to satisfy the IEEE standard for harmonic control in electric power systems.

\section{REFERENCES}

[1] F. Blaabjerg, R. Teodorescu, M. Liserre, and A. V. Timbus, "Overview of control and grid synchronization for distributed power generation systems," IEEE Transactions on Industrial Electronics., vol. 53, no. 5, pp. 1398-1409, 2006.

[2] K. Wang, Z. Qi, F. Li, L. Wang, and X. Yang, "Review of state-ofthe-art integration technologies in power electronic systems," CPSS Transactions on Power Electronics and Applications., vol. 2, no. 4, pp. 292-305, Dec. 2017.

[3] Y. Gui, W. Kim, and C. C. Chung, "Passivity-based control with nonlinear damping for type 2 STATCOM systems," IEEE Transactions on Power Systems., vol. 31, no. 4, pp. 2824-2833, 2016.

[4] Z. Zhang, J. Rodr'1guez, and R. Kennel, "Advanced control strategies for direct-drive PMSG wind turbine systems: Direct predictive torque control approaches," CPSS Transactions on Power Electronics and Applications, vol. 2, no. 3, pp. 217-225, Sep. 2017.

[5] X. Guo, W. Liu, and Z. Lu, "Flexible power regulation and currentlimited control of the grid-connected inverter under unbalanced grid voltage faults," IEEE Transactions on Industrial Electronics, vol. 64, no. 9, pp. 7425- 7432, Sep. 2017.

[6] Y. Gui, B. Wei, M. Li, J. M. Guerrero, and J. C. Vasquez, "Passivitybased coordinated control for islanded AC microgrid," Applied Energy, vol. 229, pp. 551-561, 2018.

[7] C. Wang, Z. Li, X. Si, and H. Xin, "Control of neutral-point voltage in three-phase four-wire three-level NPC inverter based on the disassembly of zero level," CPSS Transactions on Power Electronics and Applications, vol. 3, no. 3, pp. 213-222, Sep. 2018.

[8] C. H. Van Der Broeck, S. A. Richter, J. V. Bloh, and R. W. De Doncker, "Methodology for analysis and design of discrete time current controllers for three-phase PWM converters," CPSS Transactions on Power Electronics and Applications, vol. 3, no. 3, pp. 254 264, Sep. 2018.

[9] Y. Deng, Z. Xing, and Q. Zhang, “Analysis of electromagnetic transient characteristics of doubly-fed induction generator under grid voltage swell," CPSS Transactions on Power Electronics and Applications, vol. 3, no. 2, pp. 111-118, June 2018.

[10] H. Wang, W. Wu, S. Zhang, Y. He, H. S. Chung, and F. Blaabjerg, "A modified Aalborg inverter extracting maximum power from one PV array source," CPSS Transactions on Power Electronics and Applications, vol. 4, no. 2, pp. 109-118, June. 2019.

[11] X. He, H. Geng, and S. Ma, "Transient stability analysis of grid-tied converters considering PLL's nonlinearity," CPSS Transactions on Power Electronics and Applications, vol. 4, no. 1, pp. 40-49, Mar. 2019.

[12] X. Wang and F. Blaabjerg, "Harmonic stability in power electronic based power systems: Concept, modeling, and analysis," IEEE Transactions on Smart Grid, vol. 10, no. 3, pp. 2858-2870, May 2019.

[13] M. Kazmierkowski and L. Malesani, "Current control techniques for three-phase voltage-source PWM converters: a survey," IEEE Transactions on Industrial Electronics, vol. 45, no. 5, pp. 691-703, Oct. 1998.

[14] M. P. Kaz'mierkowski, R. Krishnan, and F. Blaabjerg, Control in power electronics: selected problems, Academic Press, 2002.

[15] E. Twining and D. G. Holmes, "Grid current regulation of a threephase voltage source inverter with an LCL input filter," IEEE Transactions on Power Electronics, vol. 18, no. 3, pp. 888-895, 2003.

[16] R. Teodorescu and F. Blaabjerg, "Flexible control of small wind turbines with grid failure detection operating in stand-alone and gridconnected mode," IEEE Transactions on Power Electronics, vol. 19, no. 5, pp. 1323-1332, 2004.

[17] M. Reyes, P. Rodriguez, S. Vazquez, A. Luna, R. Teodorescu, and J. M. Carrasco, "Enhanced decoupled double synchronous reference frame current controller for unbalanced grid-voltage conditions," IEEE Transactions on Power Electronics, vol. 27, no. 9, pp. 3934-3943, 2012. 
[18] Z. Li, C. Zang, P. Zeng, H. Yu, S. Li, and J. Bian, "Control of a gridforming inverter based on sliding-mode and mixed $\mathrm{H} 2 / \mathrm{H} \infty$ control," IEEE Transactions on Industrial Electronics, vol. 64, no. 5, pp. 3862$3872,2017$.

[19] L. Harnefors, M. Bongiorno, and S. Lundberg, "Input-admittance calculation and shaping for controlled voltage-source converters," IEEE Transactions on Industrial Electronics, vol. 54, no. 6, pp. 3323-3334, 2007.

[20] L. Harnefors, X. Wang, A. G. Yepes, and F. Blaabjerg, "Passivity-based stability assessment of grid-connected VSCs-An overview," IEEE Journal of Emerging and Selected Topics in Power Electronics, vol. 4, no. 1, pp. 116-125, 2016.

[21] B. Wen, D. Dong, D. Boroyevich, R. Burgos, P. Mattavelli, and Z. Shen, "Impedance-based analysis of grid-synchronization stability for three-phase paralleled converters," IEEE Transactions on Power Electronics, vol. 31, no. 1, pp. 26-38, 2016.

[22] T. Noguchi, H. Tomiki, S. Kondo, and I. Takahashi, "Direct power control of PWM converter without power-source voltage sensors," IEEE Transactions on Industry Applications, vol. 34, no. 3, pp. 473479, 1998 .

[23] M. Malinowski, M. Jasin'ski, and M. P. Kazmierkowski, "Simple direct power control of three-phase PWM rectifier using spacevector mod- ulation (DPC-SVM)," IEEE Transactions on Industrial Electronics, vol. 51, no. 2, pp. 447-454, 2004.

[24] A. Bouafia, J.-P. Gaubert, and F. Krim, "Predictive direct power control of three-phase pulsewidth modulation (PWM) rectifier using space- vector modulation (SVM)," IEEE Transactions on Power Electronics, vol. 25, no. 1, pp. 228-236, 2010.

[25] S. Vazquez, J. A. Sanchez, J. M. Carrasco, J. I. Leon, and E. Galvan, "A model-based direct power control for three-phase power converters," IEEE Transactions on Industrial Electronics, vol. 55, no. 4, pp. 1647$1657,2008$.

[26] D. Zhi and L. Xu, "Direct power control of DFIG with constant switching frequency and improved transient performance," IEEE Transactions on Energy Conversion, vol. 22, no. 1, pp. 110-118, 2007.

[27] J. Hu, L. Shang, Y. He, and Z. Zhu, "Direct active and reactive power regulation of grid-connected DC/AC converters using sliding mode control approach," IEEE Transactions on Power Electronics, vol. 26, no. 1, pp. 210-222, 2011.

[28] Y. Gui, G. H. Lee, C. Kim, and C. C. Chung, "Direct power control of grid connected voltage source inverters using port-controlled Hamilto- nian system," International Journal of Control, Automation, and Systems, vol. 15, no. 5, pp. 2053-2062, 2017.

[29] S. Larrinaga, M. Vidal, E. Oyarbide, and J. Apraiz, "Predictive control strategy for DC/AC converters based on direct power control," IEEE Transactions on Industrial Electronics, vol. 54, no. 3, pp. 1261-1271, 2007.

[30] Y. Cho and K.-B. Lee, "Virtual-flux-based predictive direct power control of three-phase PWM rectifiers with fast dynamic response," IEEE Transactions on Power Electronics, vol. 31, no. 4, pp. 33483359, 2016.

[31] S. Vazquez, A. Marquez, R. Aguilera, D. Quevedo, J. I. Leon, and L. G. Franquelo, "Predictive optimal switching sequence direct power control for grid-connected power converters," IEEE Transactions on Industrial Electronics, vol. 62, no. 4, pp. 2010-2020, 2015.

[32] H. Nian, P. Cheng, and Z. Zhu, "Coordinated direct power control of DFIG system without phase-locked loop under unbalanced grid voltage conditions," IEEE Transactions on Power Electronics, vol. 31, no. 4, pp. 2905-2918, 2016.

[33] L. Li, H. Nian, L. Ding, and B. Zhou, "Direct power control of DFIG system without phase-locked loop under unbalanced and harmonically distorted voltage," IEEE Transactions on Energy Conversion, vol. 33, no. 1, pp. 395-405, 2018.

[34] Y. Gui, C. Kim, C. C. Chung, J. M. Guerrero, Y. Guan, and J. C. Vasquez, "Improved direct power control for grid-connected voltage source converters," IEEE Transactions on Industrial Electronics, vol. 65, no. 10, Oct. 2018.

[35] Y. Gui, M. Li, J. Lu, S. Golestan, J. M. Guerrero, and J. C. Vasquez, "A voltage modulated DPC approach for three-phase PWM rectifier," IEEE Transactions on Industrial Electronics, vol. 65, no. 10, pp. 7612-7619, Oct. 2018.

[36] Y. Gui, X. Wang, F. Blaabjerg, and D. Pan, "Control of grid-connected voltage-source converters: The relationship between direct-power control and vector-current control," IEEE Industrial Electronics Magazine, vol. 13, no. 2, pp. 31-40, Jun. 2019.

[37] G. Singh, "Power system harmonics research: a survey," European Transactions on Electrical Power, vol. 19, no. 2, pp. 151-172, 2009.

[38] X. Guo, W. Wu, and Z. Chen, "Multiple-complex coefficient-filterbased phase-locked loop and synchronization technique for threephase grid-interfaced converters in distributed utility networks," IEEE Transactions on Industrial Electronics, vol. 58, no. 4, pp. 1194-1204, 2011.

[39] Y. Song and H. Nian, "Modularized control strategy and performance analysis of DFIG system under unbalanced and harmonic grid voltage," IEEE Transactions on Power Electronics, vol. 30, no. 9, pp. 4831-4842, 2015.

[40] Q. Huang and K. Rajashekara, "An improved delayed signal cancellation PLL for fast grid synchronization under distorted and unbalanced grid condition," IEEE Transactions on Industry Applications, vol. 53, no. 5, pp. 4985-4997, 2017.

[41] H. Nian and L. Li, "Direct power control of doubly fed induction generator without phase-locked loop under harmonically distorted voltage conditions," IEEE Transactions on Power Electronics, vol. 33, no. 7, pp. 5836-5846, 2018.

[42] A. Bag, B. Subudhi, and P. K. Ray, "An adaptive sliding mode control scheme for grid integration of a PV system," CPSS Transactions on Power Electronics and Applications, vol. 3, no. 4, pp. 362-371, Dec. 2018.

[43] F. Ma, Z. Zhu, J. Min, Y. Yue, and X. He, "Model analysis and sliding mode current controller for multilevel railway power conditioner under the V/v traction system," IEEE Transactions on Power Electronics, vol. 34, no. 2, pp. 1243-1253, Feb. 2019.

[44] P. Kundur, N. J. Balu, and M. G. Lauby, Power System Stability and Control, vol. 7. New York: McGraw-Hill,1994.

[45] Y. Gui, C. Kim, and C. C. Chung, "Grid voltage modulated direct power control for grid connected voltage source inverters," in American Control Conference, 2017, pp. 2078-2084.

[46] H. Akagi, E. H. Watanabe, and M. Aredes, the instantaneous power theory, Wiley Online Library, 2007.

[47] F. Z. Peng and J.-S. Lai, "Generalized instantaneous reactive power theory for three-phase power systems," IEEE Transactions on Instrumentation and Measurement, vol. 45, no. 1, pp. 293-297, 1996.

[48] Y. Gui, X. Wang, H. Wu, and F. Blaabjerg, "Voltage modulated direct power control for a weak grid-connected voltage source inverters," IEEE Transactions on Power Electronics, vol. 34, no. 11, pp. 1138311395, Nov. 2019.

[49] IEEE recommended practice and requirements for harmonic control in electric power systems, IEEE Standard 519-2014 (Revision of IEEE Std 519-1992), pp. 1-29, 2014.

[50] J. Hu, H. Nian, H. Xu, and Y. He, "Dynamic modeling and improved control of DFIG under distorted grid voltage conditions," IEEE Transactions on Energy Conversion, vol. 26, no. 1, pp. 163-175, Mar. 2011. 


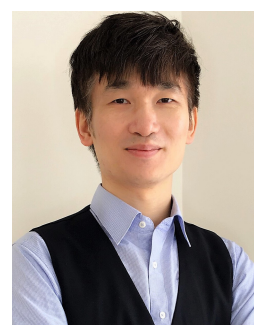

Yonghao Gui received the B.S. degree in Automation from Northeastern University, Shenyang, China, in 2009. He received the M.S. and Ph.D. degrees in Electrical Engineering from Hanyang University, Seoul, South Korea, in 2012 and 2017, respectively.

From February 2017 to November 2018, he worked with the Department of Energy Technology, Aalborg University, Aalborg, Denmark, as a Postdoctoral Researcher. Since December 2018, he has been working with the Automation \& Control Section, Department of Electronic Systems, Aalborg University, Aalborg, Denmark, where he is currently an Assistant Professor. His research interests include control of power electronics in power systems, Energy Internet, and Smart Grids.

Dr. Gui serves as an Associate Editor for the IEEE Access and the International Journal of Control, Automation and Systems. He was a recipient of the IEEE Power and Energy Society General Meeting Best Conference Paper Award in 2019.

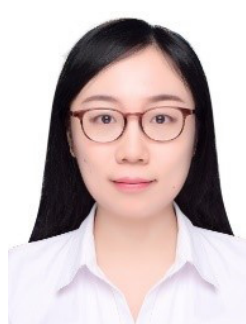

Qianwen Xu received the B.Sc. degree from Tianjin University, China in 2014 and Ph.D. degree from Nanyang Technological University, Singapore in 2018, both in Electrical Engineering. She has worked as a Research Associate in Hong Kong Polytechnic University and a postdoc research fellow in Aalborg University in 2018. Currently, she is a WallenbergNTU Presidential Postdoc Fellow in Nanyang Technological University in Singapore. Her research interests include control, stability, reliability and optimization of microgrids and smart grids.

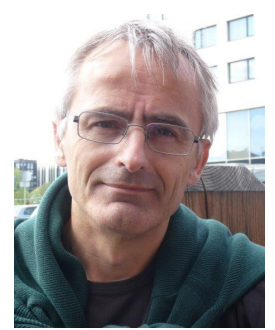

Frede Blaabjerg was with ABB-Scandia, Randers, Denmark, from 1987 to 1988 . From 1988 to 1992 , he got the Ph.D. degree in Electrical Engineering at Aalborg University in 1995 . He became an Assistant Professor in 1992, an Associate Professor in 1996, and a Full Professor of power electronics and drives in 1998. From 2017 he became a Villum Investigator. He is honoris causa at University Politehnica Timisoara (UPT), Romania and Tallinn Technical University

(TTU) in Estonia.

His current research interests include power electronics and its applications such as in wind turbines, PV systems, reliability, harmonics and adjustable speed drives. He has published more than 600 journal papers in the fields of power electronics and its applications. He is the co-author of four monographs and editor of ten books in power electronics and its applications.

He has received 31 IEEE Prize Paper Awards, the IEEE PELS Distinguished Service Award in 2009, the EPE-PEMC Council Award in 2010, the IEEE William E. Newell Power Electronics Award 2014, the Villum Kann Rasmussen Research Award 2014 and the Global Energy Prize in 2019. He was the Editorin-Chief of the IEEE Transactions on Power Electrinics from 2006 to 2012. $\mathrm{He}$ has been Distinguished Lecturer for the IEEE Power Electronics Society from 2005 to 2007 and for the IEEE Industry Applications Society from 2010 to 2011 as well as 2017 to 2018. In 2019-2020 he serves a President of IEEE Power Electronics Society. He is the Vice-President of the Danish Academy of Technical Sciences too.

He is nominated in 2014-2018 by Thomson Reuters to be between the most 250 cited researchers in Engineering in the world.

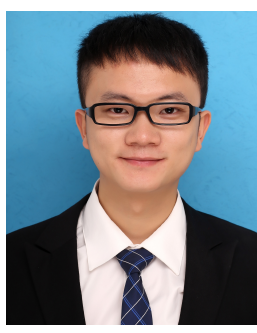

Hong Gong was born in Sichuan, China, in 1992. He received both the B.S degree and the M.S. degree from Sichuan University, Chengdu, China, in 2014 and 2017, respectively. Since 2017, he has been with the Aalborg University, Aalborg, Denmark, where he is pursuing his Ph.D. degree. His research interests include modeling and control of grid-connected converters, impedance measurement. 